\title{
1 Handling overheads: optimal multi-method invasive species control
}

3 Christopher M. Baker ${ }^{1,2,3}$. Paul R.

${ }_{4}$ Armsworth $^{4,5}$. Suzanne M. Lenhart ${ }^{4,6}$

5

6 Received: date / Accepted: date

\begin{abstract}
Invasive species are a pervasive problem worldwide and considerable resources are directed towards their control. While there are many aspects to invasive species management, deciding how to allocate resources effectively when removing them is critical. There are often multiple control methods available, each with different characteristics. For example aerial baiting has very high overhead costs, while animal trapping incurs a handling time (the trap must be reset after each capture). Here we examine a particular challenge that managers commonly face when designing eradication programs - specifically what type of control measure to rely on at different times during the eradication effort? We solve for optimal resource allocation strategies when there are two control methods available and one has overhead costs and the other has a handling time. We find that, if both controls are being used, the control with overhead costs should be used only at the beginning of a project, the other control should be used in the latter part of the project, and that there is generally an overlap where both controls are used. This contrasts with the strategies employed in many eradication projects, where ground control does not begin until aerial baiting has ceased.
\end{abstract}

Keywords optimal control $\cdot$ overhead cost $\cdot$ handling time $\cdot$ optimal control theory $\cdot$ ecological economics

\footnotetext{
1 School of BioSciences, The University of Melbourne, Australia

2 School of Biological Sciences, The University of Queensland, St Lucia, Queensland 4072, Australia

3 CSIRO, Ecosciences Precinct, Dutton Park, Queensland 4102, Australia

4 National Institute of Mathematical and Biological Sciences, The University of Tennessee, United States

5 Department of Ecology and Evolutionary Biology, The University of Tennessee, United States

6 Mathematics Department, The University of Tennessee, United States
} 
Acknowledgements

We would like to thank Michael Bode and Michael McCarthy for their input. Christopher Baker is the recipient of a John Stocker Postdoctoral Fellowship from the Science and Industry Endowment Fund. This work was assisted by attendance as a Short-term Visitor at the National Institute for Mathematical and Biological Synthesis, an Institute sponsored by the National Science Foundation through NSF Award \#DBI-1300426, with additional support from The University of Tennessee, Knoxville and the Australian Research Council Centre of Excellence for Environmental Decisions.

\section{Introduction}

Invasive species are responsible for considerable environmental and economic damage (Gurevitch and Padilla, 2004; Pimentel et al, 2005; Simberloff et al, 2013), and substantial resources are directed towards their control (Veitch and Clout, 2002). Although invasive species eradications can result in large conservation gains (Jones et al, 2016), resources to complete eradications are limited (McCarthy et al, 2012). As such, there is a large body of work focusing on allocating conservation resources as effectively as possible. In doing this, managers must decide how to use the different types of available control methods through time.

Multi-method control projects arise across a diverse range of systems. For example, the rabbit eradication on Macquarie Island, an Australian subantarctic island, used a combination of aerial poison baiting and canine-assisted ground hunting (Robinson and Copson, 2014; Terauds et al, 2014). The program started with aerial baiting and switched to ground hunting once a majority of the population was removed. Similar strategies also arise across invertebrate and weed control problems (Baker et al, 2017; Hodgson et al, 2014; Noble and Rose, 2013). The conventional wisdom is to use broad-scale aerial treatments during the early stages of the project, while the invasive species abundance is high. This is because these types of methods have very high overhead costs (i.e. the cost of using an aircraft), and the cost is only justified if many invasive individuals can be removed.

We focus on how the cost structure involved in implementing different control actions shapes the best way to combine different control actions during an invasive species eradication program. Some studies have considered aspects of this problem while pursuing other questions. However, none to our knowledge has focused specifically on the effects of the cost structure of different controls. Many analyses about invasive species control have focused singlespecies, single-control problems (Baker and Bode, 2016; Baxter et al, 2008; Chades et al, 2011; Hastings et al, 2006; Walker et al, 2015). There has also been work in designing management strategies that take into account multiple species (Bode et al, 2015; Carrasco et al, 2010; Epanchin-Niell et al, 2014; Kern et al, 2007; Lampert et al, 2014), and analyses that consider multiple 
control strategies in invasive species control (Blackwood et al, 2012; Marten and Moore, 2011) and epidemiology (Fenichel and Horan, 2007; Horan et al, 2008). However, these analyses do not allocate resources dynamically between control methods for invasive species control.

While multi-method control has been somewhat overlooked in the invasive species control literature, the analogous problem in fisheries management, where multiple fishers harvest a single resource, has been studied (Armsworth et al, 2011; Cook and McGaw, 1996). A key difference between these harvesting problems and invasive species control is that the objective in a harvesting system is often to find an equilibrium solution. However, for invasive species eradication problems the transient aspect of the problem is the most interesting. That is, how to get from the current state to zero, or very low, abundance while minimising cost (Baker and Bode, 2016). Hence, in this paper we consider the problem of eradicating an invasive species population when there are two different control methods available. In particular, we examine how overhead costs on one control and a handling time on the other affects the optimal control strategy, and we solve to see how managers should dynamically alter their resource allocation to different control methods through time. We begin by treating the optimal control problem, and then we start by solving using only one control and build in complexity, by adding handling times, a second control and finally overhead costs.

\section{Methods}

We use an ordinary differential equation to model the abundance of the invasive species, $n$, through time:

$$
\frac{\mathrm{d} n}{\mathrm{~d} t}=r n\left(1-\frac{n}{k}\right)-f_{1}\left(n, e_{1}\right)-f_{2}\left(n, e_{2}\right),
$$

with $e_{1}$ and $e_{2}$ representing the efforts of control method one and control method two, respectively. The first term is a logistic growth term, with intrinsic growth rate $r$ and carrying capacity $k$. The functions $f_{1}$ and $f_{2}$ model the rate of reduction in the abundance of the species as a function of control effort and species abundance.

Throughout this analysis, we assume that control method one has an overhead cost, while control method two incurs a handling time. Overhead costs appear when there is an additional cost to using a control method, that does not depend on the amount of effort employed. For example, during aerial baiting activities, there is a cost of hiring the aircraft that does not depend on how many hours it is used per day. Hence, there is a fixed cost (cost of hire per day) and a variable cost (cost of labour and baits). A handling time limits the total number of individuals removed per day. This models ground-based control methods such as trapping, where a certain amount of time is required to reset a trap before it can be effective again. For example, if a trap is checked 
once per day, then any single trap cannot capture more than one individual per day. While any control method would likely have some overhead cost and handling time, we consider a situation where the overhead cost of method one is much greater than method two; and similarly, the handling time of method two is much greater than method one. Hence, we only model overhead costs on method one and handling times on method two, such that we can clearly examine the differences between these two types of control.

The functional form of the rate of population removal by the two methods are given by

$$
\begin{aligned}
& f_{1}\left(n, e_{1}\right)=n \frac{\mu_{1}}{d_{1}} \log \left(1+d_{1} e_{1}\right) \\
& f_{2}\left(n, e_{2}\right)=\frac{\mu_{2} n}{d_{2}+\mu_{2} h n} \log \left(1+d_{2} e_{2}\right),
\end{aligned}
$$

where $u, d, e$ and $h$ are non-negative, and a discussion of their values is given in Section 2.3. The $\mu_{i}$ parameters set the effectiveness of control method $i$, and the $d_{i}$ parameters model marginal diminishing returns on control effort. Large values of $d_{i}$ correspond to methods where returns diminish very quickly, while in the limit $d_{i} \rightarrow 0, f_{i}$ becomes linear in $e_{i}$. We assume that control method two has a handling time, $h$ (Holling, 1959). This formulation means that at low abundances the rate of decline of the species is proportional to abundance, while at very large abundances, the rate of decline is equal to $\log \left(1+d_{2} e_{2}\right) / h$. Figure 1 shows how these two control methods depend on the invasive species abundance and the level of control effort. The effectiveness of method one does not depend on the abundance, while method two is more effective when populations are small. There is no 'correct' functional form for diminishing returns (Baker and Bode, 2016), and we choose this formulation so that the derivative of $f_{i}$ at $e_{i}=0$ is finite. The factor of $\mu_{i} / d_{i}$ in $f_{i}$ ensures that the rate of removal at low effort and low invasive species abundance scales with $\mu_{i}$ :

$$
\left.\lim _{n \rightarrow 0} \frac{1}{n} \frac{\partial f_{i}\left(n, e_{i}\right)}{\partial e_{i}}\right|_{e_{i}=0}=\mu_{i} .
$$

The management goal is to eradicate the invasive species at minimum cost. In our model, the invasive species abundance can only approach zero, so setting a final time condition that $n=0$ is not appropriate. Rather, we set the final time condition to be

$$
n(T)=1 .
$$

This is reducing the population to a threshold level below which the population would no longer be viable. For our purposes we consider $n=1$ to be conservative, and reducing a population below a certain threshold is a common management target (Blackwood et al, 2012). As the invasive species target is 

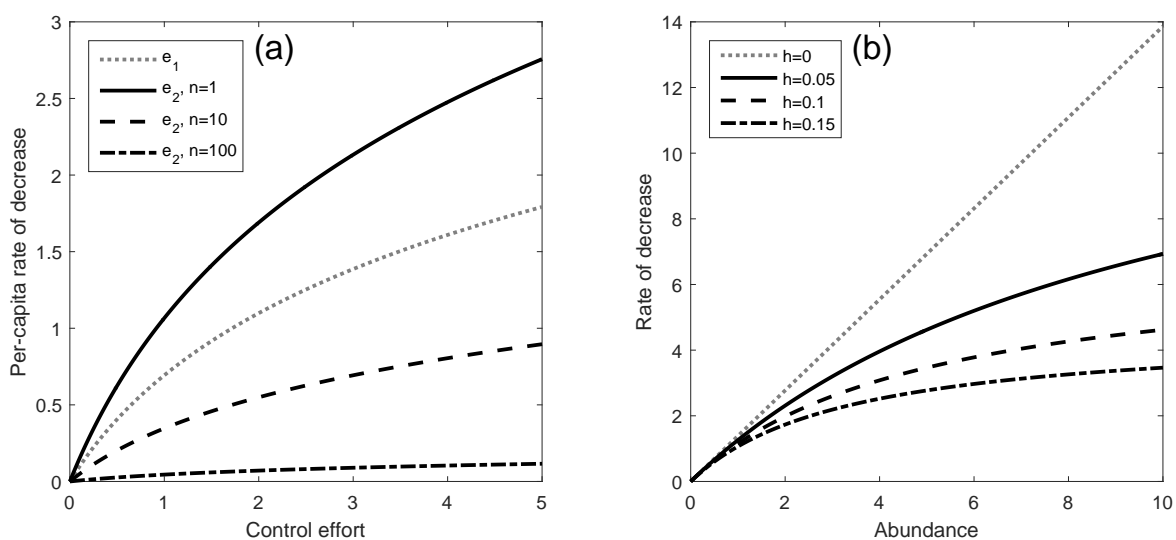

Fig. 1 (a) Per-capita rate of decrease in invasive species abundance caused by the control methods, at different starting abundance levels. The effectiveness of $e_{1}$ does not depend on the abundance, while $e_{2}$ is more effective when populations are small. (b) The rate of decline for various handling times. When $h=0$, the rate of decline increases linearly with abundance (constant per-capita decrease). However, with $h>0$, the rate of decreases increase with abundance, but is limited by the handling time. Parameter values are: $\mu_{1}=1$, $d_{1}=1, b_{1}=0, \mu_{2}=2, d_{2}=1, n=10$, and $h=0.15$, unless stated otherwise in the figure.

given by the a boundary condition, the objective functional is simply to minimise the total cost:

$$
J\left(e_{1}, e_{2}\right)=\int_{0}^{T}\left[S_{1}\left(e_{1}(t)\right)+S_{2}\left(e_{2}(t)\right)\right] e^{-\delta t} \mathrm{~d} t,
$$

where $S_{i}\left(e_{i}(t)\right)$ is the spending on $e_{i}$ at time $t$, and $e^{-\delta t}$ is economic discounting, at rate $\delta$. We also require that

$$
e_{1}(t) \geq 0 \text { and } e_{2}(t) \geq 0 \quad \forall t .
$$

In general, we use

$$
\begin{aligned}
& S_{1}\left(e_{1}(t)\right)=\mathrm{I}_{e_{1}>0} b_{1}+c_{1} e_{1}(t) \\
& S_{2}\left(e_{2}(t)\right)=c_{2} e_{2}(t),
\end{aligned}
$$

where $\mathrm{I}_{e_{1}>0}$ is an indicator variable that is equal to 1 when $e_{1}>0$ and 0 otherwise, meaning that this cost, $b_{1}$, is only incurred when $e_{1}$ is positive (Reed, 1974; Spulber, 1982). There are issues solving optimal control problem when the objective is discontinuous. To simplify the problem, we assume that $e_{1}$ will only switch on and off once. Specifically, we assume that $e_{1}$ will be positive from $t=t_{0}$ until some time, $t_{s}$, and zero until $t=T$, with $0 \leq t_{0} \leq t_{s} \leq T\left(t_{0}\right.$ is not fixed to be zero). We then solve the optimal control problem as normal (ignoring $b_{1}$, as objectives can be scaled by an arbitrary constant without 
changing the solution (Lenhart and Workman, 2007)) for a range of $t_{0}$ and $t_{s}$, in increments of 0.1 . We do this by setting $\mu_{1}=0$ when $t<t_{0}$ or $t>t_{s}$. We then include $b_{1}$ to calculate the true cost of each solution and choose the values of $t_{0}$ and $t_{s}$ that minimises the objective.

\subsection{Optimal control}

When $b_{1}=0$, the first step characterising the optimal solution is to form the Hamiltonian:

$$
H=\left[\omega n+c_{1} e_{1}+c_{2} e_{2}\right] e^{-\delta t}+\lambda\left[r n\left(1-\frac{n}{k}\right)-f_{1}\left(n, e_{1}\right)-f_{2}\left(n, e_{2}\right)\right],
$$

where $\lambda$ is the co-state variable, which satisfies the differential equation

$$
\begin{aligned}
\frac{\mathrm{d} \lambda}{\mathrm{d} t}=-\frac{\partial H}{\partial n} & =-\omega e^{-\delta t}-\lambda\left[r-\frac{2 r n}{k}-\frac{\partial f_{1}\left(n, e_{1}\right)}{\partial n}-\frac{\partial f_{2}\left(n, e_{2}\right)}{\partial n}\right] \\
& =-\omega e^{-\delta t}-\lambda\left[r-\frac{2 r n}{k}-\frac{\mu_{1}}{d 1} \log \left(1+d_{1} e_{1}\right)-\frac{d_{2} \mu_{2} \log \left(1+d_{2} e_{2}\right)}{\left(d_{2}+h \mu_{2} n\right)^{2}}\right],
\end{aligned}
$$

This equation has no initial or final time condition, and this is due to the state equation having an initial and a final time condition. The objective functional, Eq. (5), is minimised when the Hamiltonian, Eq. (8), is minimised everywhere (Lenhart and Workman, 2007). When the optimal controls are nonzero, we take the derivatives of the Hamiltonian, with respect to the controls, and set them equal to zero:

$$
\begin{aligned}
& \frac{\partial H}{\partial e_{1}}=c_{1} e^{-\delta t}-\lambda \frac{\partial f_{1}}{\partial e_{1}}=0 \\
& \frac{\partial H}{\partial e_{2}}=c_{2} e^{-\delta t}-\lambda \frac{\partial f_{2}}{\partial e_{2}}=0 .
\end{aligned}
$$

This leads to

$$
\begin{aligned}
& e_{1}(t)=\frac{n \lambda \mu_{1} e^{\delta t}-c_{1}}{c_{1} d_{1}} \\
& e_{2}(t)=\frac{d_{2} \mu_{2} n \lambda e^{-\delta t}-c_{2} d_{2}-c_{2} h \mu_{2} n}{c_{2} d_{2}\left(d_{2}+h \mu_{2} n\right)} .
\end{aligned}
$$

To ensure that this is a minimum, we see that the second derivatives of $H$ with respect to $e_{1}$ and $e_{2}$ must be positive when evaluated at all control pairs. Hence, solving the system of equations (1), (4), (9) and (11), gives the solution to our optimal control problem. 
Eq. (10) also implies that when the optimal controls are nonzero,

$$
\begin{aligned}
\frac{\left(\frac{\partial f_{1}}{\partial e_{1}}\right)}{c_{1}} & =\frac{\left(\frac{\partial f_{2}}{\partial e_{2}}\right)}{c_{2}} \\
\frac{\mu_{1}}{c_{1}\left(d_{1} e_{1}+1\right)} & =\frac{d_{2} \mu_{2}}{c_{2}\left(d_{2} e_{2}+1\right)\left(d_{2}+h \mu_{2} n\right)} .
\end{aligned}
$$

Eq. (12) is a statement about marginal benefits and costs. Here, the marginal benefits are the increase the rate of a decline due to an increase in control effort, and the marginal costs are simply $c_{1}$ and $c_{2}$. It says that, whenever there exists an internal solution (i.e. $e_{1}>0, e_{2}>0$ ), the ratio of marginal benefits and costs of each action must be equalised. As the magnitude of control effort increases the ratio of the marginal benefits and costs decreases. The exact level of effort is determined by the adjoint, $\lambda$. Solutions where one of the controls is switched off for all or part of the time occur when the ratio of marginal benefits and costs of one method is unable to match that of the other. When this occurs clearly depends on the parameter values, but it also depends on $\lambda$ and the population size $n$. Due to handling times, the marginal benefits of $e_{2}$ increase as the $n$ decreases.

\subsection{Numerical solution}

We solve the system of equations, Eqs (1), (9), (4) and (11) using boundary value problem software in MATLAB (bvp4c). Some combinations of parameters could not be solved from arbitrary initial guesses. In these cases we used continuation. That is, we started with a set of parameters that we were able to solve. We then used that solution as the initial guess for a nearby set of parameters, and we repeated this process until we arrived at a solution for our target parameter set.

\subsection{Parameter choices}

Our primary focus in the paper is on the role of overhead costs on one control variable when compared to handling time limitations on the other. We chose values for the key parameters governing the size of these cost terms to ensure the relative variation was appropriately captured. Specifically we assumed that the units of effort to be the number of (full time equivalent) people working on the project at any given time. As such, we set the cost, $c_{1}$ and $c_{2}$, to both be USD $\$ 50,000$. Eradications typically cost between USD $\$ 200,000$ and USD $\$ 2,000,000$ (Holmes et al, 2015), and aircraft hire is often around 35\% of the total project cost. Therefore we consider three values of $b_{1}$ : USD $\$ 70,000$, USD $\$ 300,000$ and USD $\$ 700,000$. Other parameters were chosen to be more indicative of a government program focused on eradicating a population of a 
fast-growing species on a small to medium sized island. Specifically, we assumed a $3 \%$ discount rate, a continuous time intrinsic rate of increase of $r=1$, and a total population size of 1000 . We use a time horizon of $T=2$.

There are no clear values to choose for the remaining parameters, and the aim in this paper is to explore how the optimal solution is affected by the control function parameters. Hence, we explore how different solutions arise from different parameter choices. We assume that both control methods should be used for at least part of the project. As the handling time reduces the efficacy of method two, we always choose $\mu_{2} \geq \mu_{1}$, and specific parameter values are given throughout the results. It would be possible to conduct experiments to determine these control parameters. Though, multiple trials would need to be conducted, with varying effort and at locations with different abundances, to get good estimates of $\mu_{2}, d_{2}$ and $h$ concurrently. Additionally, it is important to know how much altering parameters changes the optimal solution, as the best management strategy can be robust to changes in parameter values (Baker et al, 2016; Li et al, 2017).

\section{Results}

We initially solve for the optimal solution with a single control (control 2) where there is a handling time and there are no overhead costs (Figure 2). With no handling time, the control effort increases monotonically through time, which is expected from previous work (Baker and Bode, 2016). This is because as the population decreases, the amount of effort to reduce an individual increases and the growth rate is highest at small populations. However, introducing handling time causes the control effort to peak near $t=1$. This internal peak arose whenever handling time was positive, and the shape of the optimal control is remarkably similar when handling time was positive.

Next, we solved using both control methods, but without overhead costs (Figure 3). The addition of a second control means that $e_{2}$ is no longer always used throughout the whole time period, rather, as the handling time increases, it is only used in the latter part of the project. This is the time when the small invasive species population means that it can attain a high per-capita removal rate. This causes a matching change in the shape of $e_{1}$. In each solution, $e_{1}$ has an internal maximum, and the larger the handling time, the later this maximum occurs. This is because with high handling times, $e_{2}$ starts to take over later, meaning that $e_{1}$ must be used predominantly for longer.

Finally, we solved the optimal control problem with overhead costs on control one and with a handling time in control two (Figure 4). In this case we get a big qualitative shift in the optimal solution. We find that $e_{1}$ does not only decline in the latter stages of the project, provided that the overhead cost is large enough, $e_{1}$ can switch off entirely. The presence of overhead costs puts pressure on control method one to be used for a short time at high intensity. Balancing this is the effect of diminishing marginal returns on control effort, meaning that the control effort only gets very large (and for a short time 

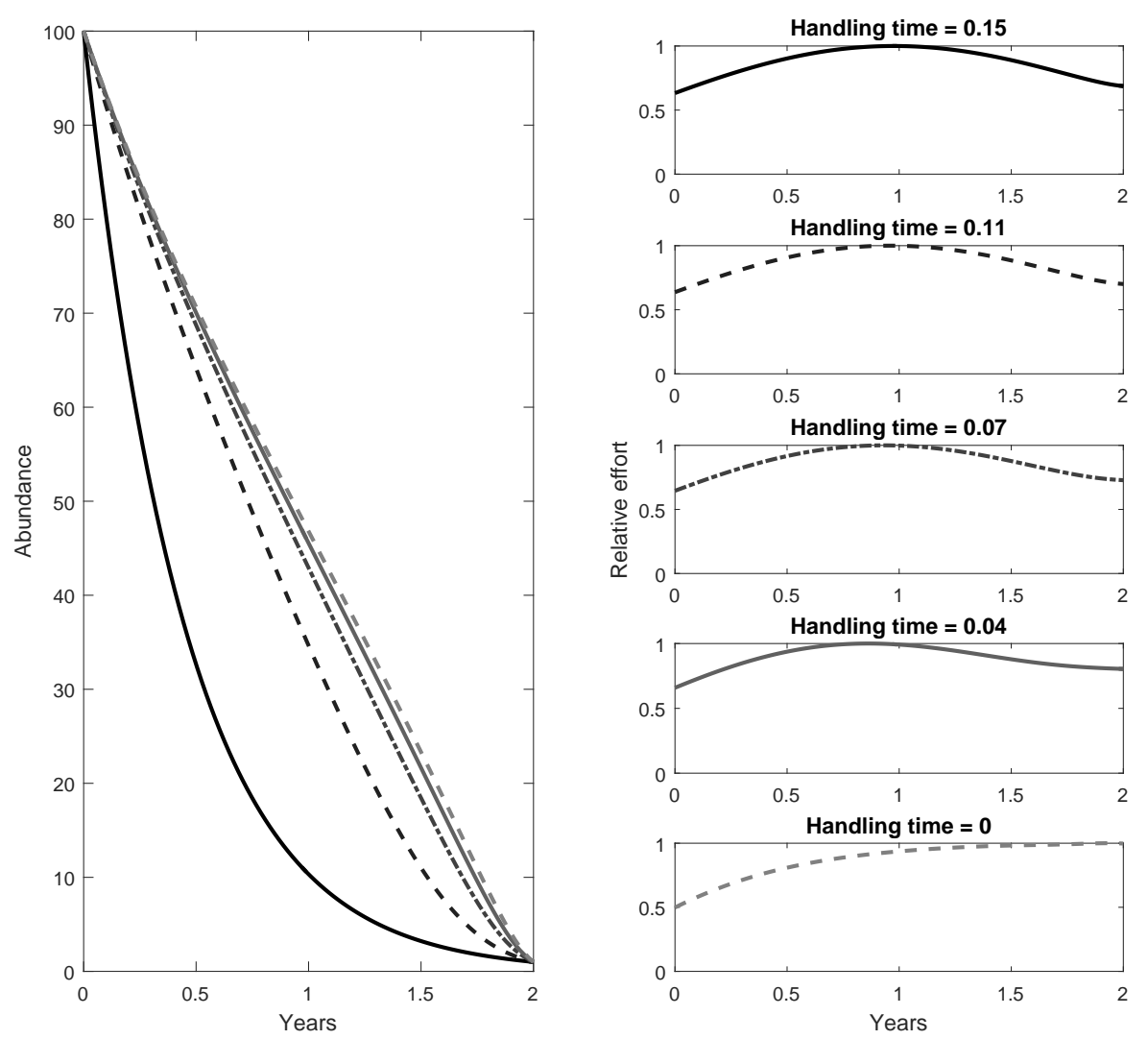

Fig. 2 The optimal control using only $e_{2}$ with varying handling time, $h$. The invasive species abundance for each solution is given in the left plot and the corresponding optimal solutions, with matching line style, are in the right panels. In each plot, the effort is scaled such that the maximum of each solution is 1 to clearly illustrate how the shape of the optimal control changes with $h$. With handling time the control effort has an internal peak, while with no handling time, the control effort increases monotonically. Parameter values are: $n(0)=1,000, r=1, k=1,000, \mu_{2}=5, d_{2}=2, c_{2}=50,000$, and $\delta=0.03$.

period) when the overhead costs become very high. Control method one is used at the beginning because control method one is most effective when the population is large. Control method one switches off once the marginal benefits Eqs. (12) and (13)). Using control method one for only part of the project one were available for the entire project. In the case where $b_{1}=300,000$, the saving is $9 \%$ and for $b_{1}=700,000$, the saving is $22 \%$. 

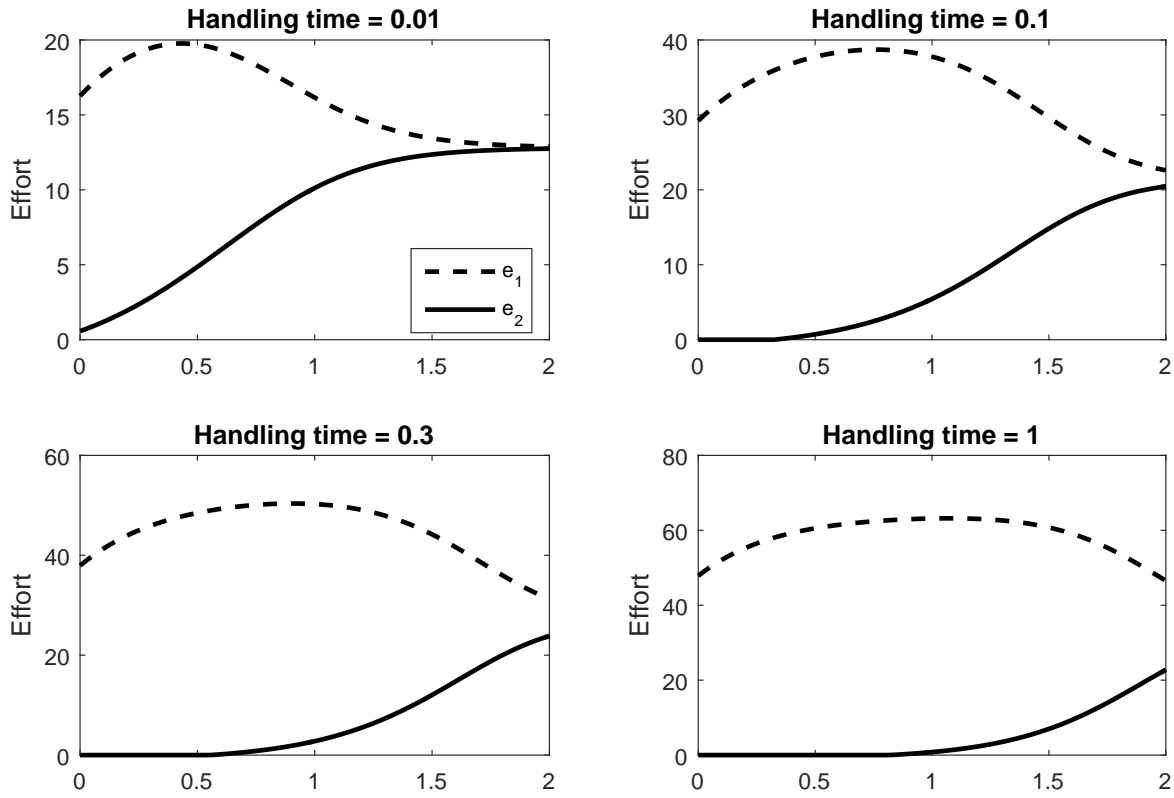

Fig. 3 The optimal allocation between two controls when there is no overhead costs $b_{1}=0$ and for varying handling time, $h$. As the handling time increases, $e_{2}$ is used less throughout the project and its use is restricted to the end. Parameter values are: $n(0)=1000, r=1$, $k=1000, \mu_{1}=1, d_{1}=1, b_{1}=0, c_{1}=50,000, \mu_{2}=1, d_{2}=1, c_{2}=50,000$, and $\delta=0.03$.
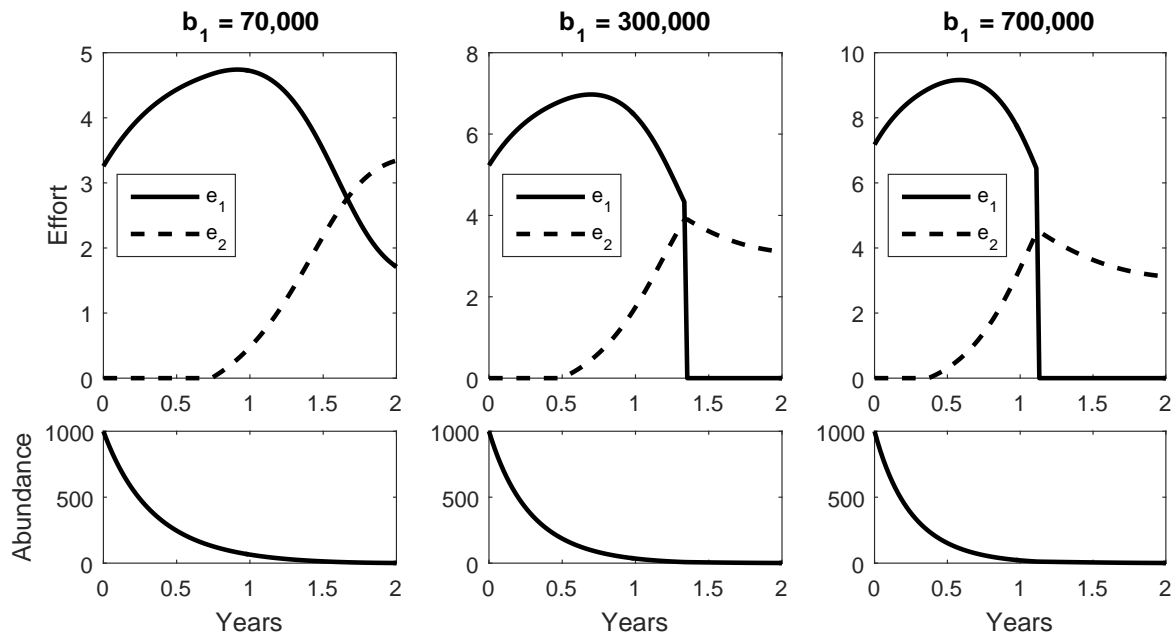

Fig. 4 The optimal allocation between two controls with handling time in $e_{2}$ and increasing overhead costs for $e_{1}$. In each case, $e_{2}$ is positive throughout the entire project, while $e_{1}$ is only positive at the beginning. The higher the overhead costs, the shorter time window that $e_{1}>0$. Parameter values are: $n(0)=1,000, r=1, k=1,000, \mu_{1}=3, d_{1}=2, c_{1}=50,000$, $h=0.05, \mu_{2}=60, d_{2}=2, c_{2}=50,000$, and $\delta=0.03$. 


\section{Discussion}

We find that the shape of the optimal solution depends on the presence of overhead costs, whether handling times are present, and the number of control methods available. Similar work without handling times has suggested that control effort should increase throughout a project when only one control method used (Baker and Bode, 2016). However, we find that introducing handling time changes this, and that, even with a small handling time, the optimal solution changes to peak near the middle of the project. This also leads to a change in the decline of the invasive species. With a handling time, the invasive species declines much more quickly at start of the project and slower at the end of the project, compared to the case without a handling time. While we focused on overhead costs and handling times, there are other interesting aspects to this problem, in particular how the species growth rate and diminishing marginal returns parameter affect the optimal solution, and these interactions are discussed in Baker and Bode (2016).

When a second control without a handling time is added, we find that the optimal solution shifts such that control method two no longer has an internal peak, rather it increases throughout. However, when we added an overhead cost to this method, we found that method one should be used from the start and for potentially only part of the project, while method two is not used immediately. Though, we note that control method two is started while method one is still in use. This result (that there is a period of overlap when both methods should be deployed) is particularly interesting because it is common for eradication projects to begin with broad-scale aerial control, which is followed by ground based control (Algar et al, 2002; Kessler, 2002; Mowbray, 2002; Macdonald and Leaman, 2002; Veitch, 2002). These results indicate that the ground based control should start while the broad scale control is ongoing, and this has occasionally been implemented on-ground (McClelland, 2002).

There are a range of other aspects to invasive species control that we did not treat here. Our analysis focused on controlling a single species, but, the removal of an invasive species often has an impact on other species present in the ecosystem (Doherty et al, 2015). For example, in some situations, control problems should be formulated with endemic species in the objective to ensure that the strategy will not only remove the invasive species, but also benefit the ecosystem (Bode et al, 2015). Our model is purely temporal and is best suited to island control projects. However, the underlying concepts about allocating resources between different control methods should carry over to more general spatial cases (Baker, 2016). Related problems include decisions about when to begin controlling a spreading invader (Sims and Finnoff, 2013; Sims et al, 2016), allocating funds towards quarantine (Moore et al, 2010; Rout et al, 2011, 2014) and allocating effort towards detecting species (Epanchin-Niell et al, 2012; Hauser and McCarthy, 2009; Mehta et al, 2007; Morrison et al, 2007; Ramsey et al, 2011; Regan et al, 2011). In general, each of these different aspects can have multiple methods, and, as our work has shown, deciding how to allocate resources between them is complicated because the optimal tem- 
poral allocation for a certain method depends both on its own characteristics (e.g., its cost structure) and what other methods are available.

Invasive species control projects are expensive and high profile (Holmes et al, 2015), and it is important to allocate resources carefully throughout a project. When multiple control methods are being used, cost-effective resource allocation relies on a strong understanding of the costs and benefits of each method. This is complicated as these will change throughout a project as the invasive species population changes. Mathematical modelling and optimisation is a good way to deal with this complexity and identify optimal strategies (Armsworth and Roughgarden, 2001). In our analyses, knowing when to cease using the method with large overheads is vital, and getting it right can lead to large savings. Despite the potential benefits, we are not aware of invasive species management projects that have explicitly incorporated this type of analysis when determining the allocation of multiple control methods. There is a strong push for conservation decision-making to be open and transparent (Blomquist et al, 2010; Donlan et al, 2014; Gregory and Long, 2009), and mathematical solutions and analysis should be a part of it.

\section{References}

Algar D, Burbridge AA, Angus GJ (2002) Cat eradication on Hermite Island, Montebello Islands, Western Australia. In: Turning the Tide: The Eradication of Invasive Species

Armsworth PR, Roughgarden JE (2001) An invitation to ecological economics. Trends in Ecology \& Evolution 16(5):229-234, DOI 10.1016/S01695347(01)02123-1

Armsworth PR, Block BA, Eagle J, Roughgarden JE (2011) The role of discounting and dynamics in determining the economic efficiency of time-area closures for managing fishery bycatch. Theoretical Ecology 4(4):513-526, DOI 10.1007/s12080-010-0093-x

Baker CM (2016) Target the source: Optimal spatiotemporal resource allocation for invasive species control. Conservation Letters pp n/a-n/a, DOI 10.1111/conl.12236

Baker CM, Bode M (2016) Placing invasive species management in a spatiotemporal context. Ecological Applications 26(3):712-725, DOI 10.1890/15-0095

Baker CM, Gordon A, Bode M (2016) Ensemble ecosystem modeling for predicting ecosystem response to predator reintroduction. Conservation Biology pp n/a-n/a, DOI 10.1111/cobi.12798

Baker CM, Hodgson JC, Tartaglia E, Clarke RH (2017) Modelling tropical fire ant (Solenopsis geminata) dynamics and detection to inform an eradication project. Biological Invasions pp 1-12, DOI 10.1007/s10530-017-1499-9

Baxter PWJ, Sabo JL, Wilcox C, McCarthy MA, Possingham HP (2008) CostEffective Suppression and Eradication of Invasive Predators. Conservation Biology 22(1):89-98, DOI 10.1111/j.1523-1739.2007.00850.x 
Blackwood JC, Berec L, Yamanaka T, Epanchin-Niell RS, Hastings A, Liebhold AM (2012) Bioeconomic synergy between tactics for insect eradication in the presence of Allee effects. Proceedings of the Royal Society B: Biological Sciences 279(1739):2807-2815, DOI 10.1098/rspb.2012.0255

Blomquist SM, Johnson TD, Smith DR, Call GP, Miller BN, Thurman WM, McFadden JE, Parkin MJ, Boomer GS (2010) Structured DecisionMaking and Rapid Prototyping to Plan a Management Response to an Invasive Species. Journal of Fish and Wildlife Management 1(1):19-32, DOI 10.3996/JFWM-025

Bode M, Baker CM, Plein M (2015) Eradicating down the food chain: optimal multispecies eradication schedules for a commonly encountered invaded island ecosystem. Journal of Applied Ecology pp 571-579, DOI 10.1111/13652664.12429

Carrasco LR, Mumford JD, MacLeod A, Knight JD, Baker RHA (2010) Comprehensive bioeconomic modelling of multiple harmful non-indigenous species. Ecological Economics 69(6):1303-1312, DOI 10.1016/j.ecolecon.2010.02.001

Chades I, Martin TG, Nicol S, Burgman MA, Possingham HP, Buckley YM (2011) General rules for managing and surveying networks of pests, diseases, and endangered species. Proceedings of the National Academy of Sciences 108(20):8323-8328, DOI 10.1073/pnas.1016846108

Cook BA, McGaw RL (1996) Sport and Commercial Fishing Allocations for the Atlantic Salmon Fisheries of the Miramichi River. Canadian Journal of Agricultural Economics/Revue canadienne d'agroeconomie 44(2):165-171, DOI 10.1111/j.1744-7976.1996.tb00191.x

Doherty TS, Dickman CR, Nimmo DG, Ritchie EG (2015) Multiple threats, or multiplying the threats? Interactions between invasive predators and other ecological disturbances. Biological Conservation 190:60-68, DOI 10.1016/j.biocon.2015.05.013

Donlan CJ, Luque GM, Wilcox C (2014) Maximizing return on investment for island restoration and species conservation. Conservation Letters pp 171179, DOI 10.1111/conl.12126

Epanchin-Niell RS, Haight RG, Berec L, Kean JM, Liebhold AM (2012) Optimal surveillance and eradication of invasive species in heterogeneous landscapes. Ecology Letters 15(8):803-812, DOI 10.1111/j.14610248.2012.01800.x

Epanchin-Niell RS, Brockerhoff EG, Kean JM, Turner J (2014) Designing costefficient surveillance for early detection and control of multiple biological invaders. Ecological Applications DOI 10.1890/13-1331.1

Fenichel EP, Horan RD (2007) Jointly-Determined Ecological Thresholds and Economic Trade-Offs in Wildlife Disease Management. Natural Resource Modeling 20(4):511-547, DOI 10.1111/j.1939-7445.2007.tb00219.x

Gregory R, Long G (2009) Using structured decision making to help implement a precautionary approach to endangered species management. Risk Analysis 29(4):518-532, DOI 10.1111/j.1539-6924.2008.01182.x 
Gurevitch J, Padilla DK (2004) Are invasive species a major cause of extinctions? Trends in Ecology \& Evolution 19(9):470-474, DOI 10.1016/j.tree.2004.07.005

Hastings A, Hall RJ, Taylor CM (2006) A simple approach to optimal control of invasive species. Theoretical Population Biology 70(4):431-435, DOI 10.1016/j.tpb.2006.05.003

Hauser CE, McCarthy MA (2009) Streamlining search and destroy: costeffective surveillance for invasive species management. Ecology Letters 12(7):683-692, DOI 10.1111/j.1461-0248.2009.01323.x

Hodgson JC, Abbott KL, Clarke RH (2014) Eradication plan Tropical Fire Ant Solenopsis geminata at Ashmore Reef Commonwealth Marine Reserve. Tech. rep., Monash University

Holling CS (1959) Some Characteristics of Simple Types of Predation and Parasitism. The Canadian Entomologist 91(07):385-398, DOI 10.4039/Ent91385-7

Holmes ND, Campbell KJ, Keitt BS, Griffiths R, Beek J, Donlan CJ, Broome KG (2015) Reporting costs for invasive vertebrate eradications. Biological Invasions 17(10):1-13, DOI 10.1007/s10530-015-0920-5

Horan RD, Wolf CA, Fenichel EP, Mathews KH (2008) Joint Management of Wildlife and Livestock Disease. Environmental and Resource Economics 41(1):47-70, DOI 10.1007/s10640-007-9180-x

Jones HP, Holmes ND, Butchart SHM, Tershy BR, Kappes PJ, Corkery I, Aguirre-Muoz A, Armstrong DP, Bonnaud E, Burbidge AA, Campbell K, Courchamp F, Cowan PE, Cuthbert RJ, Ebbert S, Genovesi P, Howald GR, Keitt BS, Kress SW, Miskelly CM, Oppel S, Poncet S, Rauzon MJ, Rocamora G, Russell JC, Samaniego-Herrera A, Seddon PJ, Spatz DR, Towns DR, Croll DA (2016) Invasive mammal eradication on islands results in substantial conservation gains. Proceedings of the National Academy of Sciences p 201521179, DOI 10.1073/pnas.1521179113

Kern DL, Lenhart S, Miller R, Yong J (2007) Optimal control applied to nativeinvasive population dynamics. Journal of Biological Dynamics 1(4):413426, DOI 10.1080/17513750701605556

Kessler D (2002) Eradication of feral goats and pigs and consequences for other biota on Sarigan Island, Commonwealth of the Northern Mariana Islands. In: Turning the Tide: The Eradication of Invasive Species

Lampert A, Hastings A, Grosholz ED, Jardine SL, Sanchirico JN (2014) Optimal approaches for balancing invasive species eradication and endangered species management. Science 344(6187):1028-1031, DOI $10.1126 /$ science. 1250763

Lenhart S, Workman JT (2007) Optimal Control Applied to Biological Models. Mathematical and Computational Biology Series, Chapman \& Hall/CRC, London

Li SL, Bjrnstad ON, Ferrari MJ, Mummah R, Runge MC, Fonnesbeck CJ, Tildesley MJ, Probert WJM, Shea K (2017) Essential information: Uncertainty and optimal control of Ebola outbreaks. Proceedings of the National Academy of Sciences 114(22):5659-5664, DOI 10.1073/pnas.1617482114 
Macdonald N, Leaman AA (2002) An attempt to eradicate feral goats from Lord Howe Island. In: Turning the Tide: The Eradication of Invasive Species

Marten AL, Moore CC (2011) An options based bioeconomic model for biological and chemical control of invasive species. Ecological Economics 70(11):2050-2061, DOI 10.1016/j.ecolecon.2011.05.022

McCarthy DP, Donald PF, Scharlemann JPW, Buchanan GM, Balmford A, Green JMH, Bennun LA, Burgess ND, Fishpool LDC, Garnett ST, Leonard DL, Maloney RF, Morling P, Schaefer HM, Symes A, Wiedenfeld DA, Butchart SHM (2012) Financial Costs of Meeting Global Biodiversity Conservation Targets: Current Spending and Unmet Needs. Science 338(6109):946-949, DOI 10.1126/science.1229803

McClelland PJ (2002) Eradication of Pacific rats (Rattus exulans) from Whenua Hou Nature Reserve (Codfish Island), Putauhinu and Rarotoka Islands, New Zealand. In: Turning the Tide: The Eradication of Invasive Species

Mehta SV, Haight RG, Homans FR, Polasky S, Venette RC (2007) Optimal detection and control strategies for invasive species management. Ecological Economics 61(23):237-245, DOI 10.1016/j.ecolecon.2006.10.024

Moore JL, Rout TM, Hauser CE, Moro D, Jones M, Wilcox C, Possingham HP (2010) Protecting islands from pest invasion: optimal allocation of biosecurity resources between quarantine and surveillance. Biological Conservation 143(5):1068-1078, DOI 10.1016/j.biocon.2010.01.019

Morrison SA, Macdonald N, Walker K, Lozier L, Shaw MR (2007) Facing the dilemma at eradication's end: uncertainty of absence and the Lazarus effect. Frontiers in Ecology and the Environment 5(5):271-276, DOI 10.1890/15409295(2007)5[271:FTDAEE]2.0.CO;2

Mowbray D (2002) Eradication of introduced Australian marsupials (brushtail possum and brushtailed rock wallaby) from Rangitoto and Motutapu Islands, New Zealand. In: Turning the Tide: The Eradication of Invasive Species

Noble M, Rose M (2013) Managing African boxthorn (Lycium ferocissimum) in Australia. Tech. rep., Department of Agriculture, Fisheries and Forestry, Tasmania

Pimentel D, Zuniga R, Morrison D (2005) Update on the environmental and economic costs associated with alien-invasive species in the United States. Ecological Economics 52(3):273-288, DOI 10.1016/j.ecolecon.2004.10.002

Ramsey DSL, Parkes JP, Will D, Hanson CC, Campbell KJ (2011) Quantifying the success of feral cat eradication, San Nicolas Island, California. New Zealand Journal of Ecology 35(2):163-173

Reed WJ (1974) A stochastic model for the economic management of a renewable animal resource. Mathematical Biosciences 22:313-337, DOI 10.1016/0025-5564(74)90097-2

Regan TJ, Chads I, Possingham HP (2011) Optimally managing under imperfect detection: a method for plant invasions. Journal of Applied Ecology 48(1):76-85, DOI 10.1111/j.1365-2664.2010.01915.x 
Robinson SA, Copson GR (2014) Eradication of cats (Felis catus) from subantarctic Macquarie Island. Ecological Management \& Restoration 15(1):34-40, DOI 10.1111/emr.12073

Rout TM, Moore JL, Possingham HP, McCarthy MA (2011) Allocating biosecurity resources between preventing, detecting, and eradicating island invasions. Ecological Economics 71:54-62, DOI 10.1016/j.ecolecon.2011.09.009

Rout TM, Moore JL, McCarthy MA (2014) Prevent, search, or destroy? A partially observable model for invasive species management. Journal of Applied Ecology pp n/a-n/a, DOI 10.1111/1365-2664.12234

Simberloff D, Martin JL, Genovesi P, Maris V, Wardle DA, Aronson J, Courchamp F, Galil B, Garca-Berthou E, Pascal M, Pyek P, Sousa R, Tabacchi E, Vil M (2013) Impacts of biological invasions: what's what and the way forward. Trends in Ecology \& Evolution 28(1):58-66, DOI $10.1016 /$ j.tree.2012.07.013

Sims C, Finnoff D (2013) When is a wait and see approach to invasive species justified? Resource and Energy Economics 35(3):235-255, DOI 10.1016/j.reseneeco.2013.02.001

Sims C, Finnoff D, Shogren JF (2016) Bioeconomics of invasive species: using real options theory to integrate ecology, economics, and risk management. Food Security 8(1):61-70, DOI 10.1007/s12571-015-0530-1

Spulber DF (1982) Adaptive harvesting of a renewable resource and stable equilibrium. In: Mirman L, Spulber DF (eds) Essays in the economics of renewable resources., North-Holland Publishing, Amsterdam., pp 117 - 139

Terauds A, Doube J, McKinlay J, Springer K (2014) Using long-term population trends of an invasive herbivore to quantify the impact of management actions in the sub-Antarctic. Polar Biology 37(6):833-843, DOI $10.1007 / \mathrm{s} 00300-014-1485-\mathrm{y}$

Veitch CR, Clout MN (2002) Turning the tide: the eradication of invasive species (proceedings of the international conference on eradication of island invasives). IUCN SCC Invasive Species Specialist Group, IUCN, Gland, Switzerland and Cambridge, UK

Veitch D (2002) Eradication of Norway rats (Rattus norvegicus) and house mouse (Mus musculus) from Motuihe Island, New Zealand. In: Turning the Tide: The Eradication of Invasive Species

Walker AN, Poos JJ, Groeneveld RA (2015) Invasive species control in a onedimensional metapopulation network. Ecological Modelling 316:176-184, DOI 10.1016/j.ecolmodel.2015.08.015 